Journal of the Scholarship of Teaching and Learning, Vol. 21, No. 2, June 2021, pp. 58-78. doi: 10.14434/josotl.v21i2.28597

\title{
Effects of Faculty and Staff Connectedness on Student Self-Efficacy
}

\author{
S. Nicole Ferguson \\ University of Colorado Colorado Springs
}

\begin{abstract}
Student self-efficacy is an important part of determining a student's ability to perform well in school. This research study is a mixed-method approach to determining whether student self-efficacy is impacted by the relationships students have with faculty and staff on a college campus. Previous research indicates that student success is related to environment as well as self-efficacy. Using a grounded theory approach, this research extrapolates what factors matter most to student success. The study shows quantitatively that student self-efficacy improves with age. Students indicated factors contributing to their success include better training of faculty and staff, better support of the school environment, and that faculty are more supportive than staff in most instances. Essentially, it is imperative that faculty be present and supportive of students in their college careers as the faculty are those on the campus whom students most look to for success. These findings indicate that more research should be conducted on roles of staff and how they contribute to higher learning, as well as what resources could be put into place to better support students and that faculty and administrators would be most effective in student success by seeking out knowledge to make them more aware of student need and the use of student advocacy in the university environment.
\end{abstract}

Keywords: self-efficacy, connectedness, college relationships, interactions, faculty, staff

\section{Introduction}

While research has been conducted with regard to student self-efficacy and student success, fewer attempts have been made to review the impact of these factors on students of color and, generally, staff relationships with students are rarely considered. Gnebola (2015) studied the correlation between faculty-student interaction and academic self-efficacy, finding that they are related, but was unable to adequately identify the effect of race and ethnicity on these findings. Through a mentorship study, DeFreitas and Bravo (2012) determined that there is a positive relationship among students of color and their connectedness to faculty relevant to their academic achievement but did not identify relationships students may have with staff on their campuses. Because existing research tends to exclude staff interactions in student success and because there is little information about how these interactions may impact student GPA, I used a grounded theory model to determine an emerging and authentic theory behind student success. The study that follows is a mixed-methods approach grounded in a postpositivist model in an effort to generate knowledge from students based on their own experiences with regard to their personal self-efficacy. The theory that a connection with faculty and staff has an impact on student success was tested and reviewed through data collection. Additionally, I collected demographic data and used multiple regression techniques in SPSS to determine what, if any, factors may also impact student success in this environment by comparing demographics to self-efficacy scores and student self-reported GPA. This study sought to answer the following questions:

1. To what extent might faculty and staff interactions be correlated student success?

2. How do underrepresented students perceive their interactions with faculty and staff?

3. How do students perceive these interactions as influencing their success, retention, and/or GPA? 


\section{Literature Review}

This study was conducted to find what ways students on college campuses feel strongly about their ability to be successful and to find what factors may contribute to that success. As a means of testing this belief in achievement, self-efficacy was selected as an assessment tool. Self-efficacy, specifically, perceived self-efficacy is the product of one's belief about their ability to complete a task at a specified level (Bandura, 1994). Self-efficacy can determine feelings, thoughts, and even motivating factors (Bandura, 1994). A person's efficacious belief can impact their accomplishments, stress levels, and even their association with depression (Bandura, 1994). Positive self-efficacy occurs through four channels: resiliency, social models, social persuasion, and stress reduction (Bandura, 1994). For the purposes of this study, comparisons in this realm will be most closely related to the social aspect of Bandura's theory. Final thoughts extracted from Bandura's (1994) research include the notion of collective efficacy, in which group and organizational integration can increase or decrease self-efficacy, which is inclusive of faculty and staff being a part of the systems in which self-efficacious students are members.

\section{Beyond Bandura}

Other researchers engaged in illuminating the concept of self-efficacy for students have determined that self-efficacy is not only a factor of one's environment, but also of their ability to manage that environment in ways to increase their success (Pajares, 1996). In reviewing Pajares' findings, it would be in a student's best interest to become cordial with their faculty and staff on campus in an effort to increase their self-efficacy. Triadic reciprocity is a notion that values the relationship between a student's personal life, behavior, and environment (Pajares, 1996). In this model, it is important to be mindful of a student's demographic data, as was collected in this study, and to get an idea of the impact their lives may have on their perceptions of the relationships they have with others on campus. These pieces, when viewed holistically, should give a researcher an idea of where the student could place themselves on a self-efficacy scale.

When considering the conditions surrounding a student, research suggests educators can infer students' ability to regulate their self-efficacy (Baker, 2013; Brown, Ganesan, \& Challagalla, 2001; Gnebola, 2015). For example, if a student has a low level of inquiry, or is fearful of interacting with faculty or staff and their ability to monitor or observe the behaviors occurring around them, they will be lower performing and have lower self-efficacy (Brown et al., 2001). If a student feels confident communicating with those in their system, be it faculty, staff, or peers, the student's level of inquiry will be high and their monitoring ability will be high which should result in the optimal level of selfefficacy and achievement for the student (Brown et al., 2001). Ultimately, if university faculty and staff provide positive learning environments for students within which they feel comfortable with inquiry, not only would scholastic anxiety be reduced, but students could also have a more positive sense of self-efficacy and higher levels of motivation (Zimmerman, 2000). In addition to faculty and staff fostering this supportive environment in an effort to increase self-efficacy, additional efforts have been made to determine effects of other external factors that may impact a student's self-efficacy, namely social interaction with others on campus such as their friends, peers, or faculty and staff.

\section{College Environment}

While understanding the conditions in which students experience college, researchers would be remiss to not consider the way students perceive those conditions based on their personal experiences. Research has shown that students and their interaction with their environment through social

Journal of the Scholarship of Teaching and Learning, Vol. 21, No. 2, June 2021. josotl.indiana.edu 
integration and academic integration are both vital to persistence in college (Tinto, 1975). One of the largest predictors of college dropout is a student's social interaction (Tinto, 1975). If a student feels unwelcome in their environment, they are likely to leave. This finding was echoed by other studies that indicate that feelings of connection to others can increase college success (Baker, 2013), and finding other faculty or staff on campus who share similar characteristics such as race and ethnicity can help increase student self-efficacy related to both peers and university faculty or staff (DeFreitas, 2012). The impression that race and ethnicity may play a large part in student self-efficacy is also one that cannot be ignored.

Research on faculty and student interaction reveals that students of color report more positive interactions with faculty who look like them, particularly, the same race or ethnicity as they identify (Pajares, 1996). Students also report an increased level of comfort when speaking to a faculty member with whom they believe they have similarities, which results in higher academic performance (Baker, 2013; DeFreitas, 2012). With correlations identified between environment, connectedness, and selfefficacy; creating a foundation requires that researchers seek to understand how these factors interact and can result in student success.

It is clear that extensive research has been conducted on self-efficacy and its use as an assessment tool for educational success. What remains to be considered are the environmental factors which also play a part in student success. This study is used to compare these factors and determine what impact these outside factors may have on students' belief in themselves and their abilities to navigate college life and their environment. These interactions can be further extracted through careful consideration of the social impact of these relationships on student success through the use of social capital.

\section{Theoretical Framework}

A common cliché is that life is not about what you know but who you know. This notion explains the importance of social capital in this body of research. Social capital refers to the relationships people may have with others and how those relationships can provide mutual benefit to those in the relationship through shared resources, e.g. networking, knowledge sharing, etc. (Coleman, 1990). Here, social capital is considered in relation to how connected the students are to their social environment and those in the social system of college. Systems can be altered based upon the social interaction that occurs within them and those systems ultimately influence society as a whole. When considering student connectedness to faculty and staff on campus, I identify themes regarding connectedness on student self-efficacy and how this social interaction aids in student success. Knowing the effects of social interaction on systems and success, social capital was selected to inform the research questions of 1 . To what extent might faculty and staff interaction be correlated to student success?, 2. How do underrepresented students perceive their interactions with faculty and staff?, and 3. How do students perceive these interactions as influencing their success, retention, and/or GPA?

Specifically, it is important to consider the social gains students may experience through these interactions, like building new networks to help them find employment after graduation, or how students, who might otherwise feel like outsiders, become more integrated in the social system by finding those like them to create bonds and foster their belief that they can succeed in college. Social capital has been clearly linked to access to information, access to resources, the ability to find and obtain a career, and greater satisfaction in the career sought (Seibert, Kraimer, \& Linden, 2001). I believe this information can be directly linked to student education through the use of information, resources, and personal and professional development. Students who have or gain social capital will feel more connected to their environment and perceive their self- efficacy more highly than those who do not. This social capital can be the catalyst for what makes students begin to believe in themselves

Journal of the Scholarship of Teaching and Learning, Vol. 21, No. 2, June 2021. josotl.indiana.edu 
and allow them to persist, which should lead to career attainment and successful completion of the goals a student had when entering college. This notion lends itself to the idea that an underlying theory may identify how these relationships and environment could predict student success and high selfefficacy.

\section{Methodology}

Understanding that environment and social structure may be an underlying cause for student success, I chose a grounded theory approach for this study to determine if there is some theory that could explain these relationships. Grounded theory is defined as the ability to construct a theory using data gathering and analysis (Corbin \& Strauss, 2007). Grounded theory differs from other methodologies in that it relies on coding and categories collected to provide the basis for a new theory (Corbin \& Strauss, 1990). Grounded theory, in data analysis, requires that collected data be analyzed through inductive means, and frequent memoing and theme classification through the organization of data, notes, and coding (Creswell, 2017).

For grounded theory researchers, coding requires collecting data and searching for important paragraphs or statements made by participants (Glaser \& Strauss, 1967). Multiple phases of coding are used to identify the core theory that can be used to explain the phenomena identified in the research which, here, are the causal conditions or the relationships that exist and serve to regulate selfefficacy (Glaser \& Strauss, 1967). These phases are open coding, in which data is collected to identify major categories; axial coding, in which the researcher begins to narrow down the open codes found and focuses on individual pieces of information that may begin to identify the theory forming; and lastly, selective coding, in which the researcher must identify a hypothesis or explanation for the previously determined code selection as a means to determine a theory (Creswell, 2017). This method requires the iterative collection of emergent data and themes through cyclical collection and reapplication of themes and codes (Creswell, 2017). By following these structures toward data analysis, the grounded theory researcher can more easily identify the theory they are seeking to discover and use these methods to revisit theme development throughout the data collection process (Charmaz, 2006).

Strauss and Corbin (1990) explain grounded theory data analysis as building a story. In order to tell the story and identify the theory through grounded theory analysis, I share the information from participants by collecting the data they shared with me and looking at themes and categories to develop the theory behind what they told me. I continued to collect this data and attempted to tell the story of my participants until saturation was met. I knew I had achieved theoretical saturation once the story was fully developed and my participants were no longer telling me any new details of their story (Guest, Bunce, \& Johnson, 2006).

Throughout my data analysis, I sought out themes and commonality among my participants and used that information to indicate patterns that described their relationships with faculty and staff and what impact they believe those relationships have on their success in college. Because I used participant interviews to identify what makes them perceive success and self-efficacy, grounded theory seemed like the most logical version of coding to use. Knowing that this area of research is something that has not yet existed, my hope was to identify a theory that did not yet exist. After conducting this study, it seems as though phenomenology may have also been an ideal methodology for this study. Because that was not the lens I began my research with, I maintained my intentions through grounded theory in this study. Further research may benefit from a phenomenological approach.

In addition to defining the best theoretical framework and methodology to use, it is important to share further aspects of the study which could aid in the understanding and replication of the information provided. In the following section, I will share more information about the research site, data collected, surveys used, and the interviews conducted.

Journal of the Scholarship of Teaching and Learning, Vol. 21, No. 2, June 2021. josotl.indiana.edu 


\section{Research Site}

Due to my research being supported by the educational institution I am enrolled in and data collection being conducted at another campus, I obtained IRB approval from both institutions as well as a letter of access from my data collection campus. Data was collected from students currently enrolled at a regional comprehensive Hispanic Serving Institution (HSI). My research site was a four-year public university with an enrollment of approximately 5,000 students and an on campus living population of approximately 800 according to their website. The nature of this data collection site is such that the students are generally from the surrounding areas and are largely commuter students. According to the data collection site's website, other campus demographics include a 53\% female population, 49\% White population, and an average age of 24 . Because the campus is an HSI, their website indicates that $34 \%$ of the student population identifies as Hispanic and approximately $32 \%$ of the students on the campus are first-generation. Limitations will be explored later in this study to determine if these institutional characteristics impact the study.

\section{Data Collection}

Four sections of courses in the Psychology department, ranging from first year courses to higher level courses, were selected due to large class sizes and the ability provide a purposeful sample to reach students of various backgrounds. My intention was that this source of data would be information-rich, and random sampling was reflected upon to provide a better understanding of the nature of the culture I am studying (Jones, Torres, \& Arminio, 2006). Random sampling is preferred to generalize data collected in a way that can likely be a predictor of the larger population (Jones et al., 2006). Random sampling also allowed me the opportunity to reach a broad sample of students which was completed through the use of surveys and interviews.

Surveys. In this study, surveys yielded a sample of 135 students with various characteristics that could be applied to the greater population of college students on the campus (see Appendix 1 for the assessment tool used). Demographic data was requested from students who volunteered to participate as well as the completion of a 13-item Likert scale student self-efficacy measurement tool created by Gaumer, Erikson, and Noonan (2018). This measure has been determined to be highly reliable with an alpha of .894 . Scores retrieved from the questionnaire were compared against student demographics and their connections to faculty and staff to determine which of these factors contributed to higher or lower self-efficacy ratings. The data collection materials also included an informed consent document explaining the time expected to be spent on the materials and their ability to opt out of the study at any time. Completed surveys asked students to indicate an interest in a follow-up interview. Thirty-four students shared their email addresses and were willing to participate in the second phase of data collection through qualitative interviews.

Interviews. Students who indicated interest in continued participation were contacted via email and asked to schedule a time period of one hour in which they could meet with me and share their experiences with faculty and staff connectedness. Of the 34 participants who indicated an interest in following up, four emails were returned due to possibly being entered incorrectly or the participant's email being illegible. Of the remaining 30 interested participants, ten responded and scheduled an interview. Two additional emails were sent to students who previously indicated interest, however, no responses were received. Further information about this data collection process will be addressed in the limitations section.

Individual interviews were conducted as opposed to focus groups to prevent group think and garner honest feedback from individual participants that may not have been explored in the survey. I also expected students to identify sources of both positive and negative experiences they have had and

Journal of the Scholarship of Teaching and Learning, Vol. 21, No. 2, June 2021. josotl.indiana.edu 
compare those experiences to other responses in an effort to identify a theme. For the interview sessions, I reserved a room in the library on campus, which is a neutral space and located away from the faculty offices and staff spaces. This was intentionally done to prevent any kind of influence on the students or perception of coercion (Jacob \& Furgerson, 2012). Participants were given a second informed consent form that explained the qualitative portion of the study and their ability to skip any questions they do not wish to answer and their ability to opt out at any time. Using a predetermined script, I began by sharing the information with each student about the study and then reminded them what I intend to do with the information gathered. I then asked a series of semi-structured questions and allowed the participants to guide the conversation based on their experiences (see Appendix 2 for interview protocol used). Questions were formulated to determine to what extent participants believed their interactions with faculty and staff influence their success and self-efficacy. Interviews were recorded, and interviewees were assigned a pseudonym. Themes were identified throughout each interview to assist in the development of a grounded theory related to student self-efficacy and the research questions guiding this study.

\section{Data Analysis Strategies}

My overarching data analysis strategy for this study was to collect quantitative data and qualitative data to compare and contrast during my attempt to identify a theory related to student self-efficacy and student interactions. All the while, my collection required that I be mindful of my trustworthiness and credibility. What follows is a brief overview of how I analyzed the data collected.

For this study, I collected demographic data and conducted quantitative comparisons among the number of hours spent with faculty and staff compared to the students' self-reported GPA. I also compared race/ethnicity, gender, and socioeconomic status to the students' number of interactions with faculty and staff compared to their GPA through multiple regression. I also used the aforementioned self-efficacy scale to determine how successful students believe they are and compared that data to the demographics provided in a multiple regression. Once these patterns were formed, I began to analyze my data.

To analyze and interpret the one-on-one interviews with participants, I began by memoing during the interviews and extracting concepts they exhibited that presented as a theme or related to theory (Strauss, 1987). I listened for cues throughout the interviews to understand what the students believed was important to them in regard to their success and their relationships with faculty and staff and used that information to inform future interviews (Corbin \& Strauss, 1990). I noted when students were discussing faculty relationships or staff connections so that those could easily be identified and parsed out in the findings section. I also listened for keywords during the interviews that could indicate important factors and other salient information I could collect. Throughout the memoing process, I was mindful of the participants' body language and non-verbal cues to help me see what things seemed to bring them comfort and what may cause them anxiety or distress. Those non-verbal cues were noted in my memoing process in an effort to continue the search for meaning in the participants' behavior as well as with their words (Hatch, 2002). After data was collected during the interviews, I immediately began to process the information to ensure that no patterns were missed, so that I could take notice of my notes and memos and ensure accuracy, and to see if there may have been cues I missed during the interview.

For the pattern detection process, I developed the strategy suggested by Saldaña (2009) in that I completed multiple cycles of coding. I first sought out larger contexts, paragraphs, sentences, and later, during a secondary cycle, distilled these larger sections down to single words or phrases that could be construed across multiple participants. Through the patterns detected (a need for faculty/staff training, concerns about institutional culture, and support needs as defined in later

Journal of the Scholarship of Teaching and Learning, Vol. 21, No. 2, June 2021. josotl.indiana.edu 
sections), I began the theory development process. While it was important for me to search for frequency and patterns across my data, I also searched for discrepancies in the information provided by participants to determine any disconfirmation between participants and seek to understand the reason behind those differences (for example, did students of color have a different experience than their counterparts, did students with higher GPAs experience different interactions than those with lower grades, etc.). This allowed me to notice any information that may be significantly absent, which could lead me to search for meaning behind what is missing (Corbin \& Strauss, 1990). If certain students with shared characteristics had a different perception of the topic, I sought to determine what factors might be the cause of these students' distinctive reports. Aside from frequency, I was also looking for sequences, relationships to other events (correspondence), and any efforts of causation that existed (Saldaña, 2009). Because I used a grounded theory approach for this research, it was important for me to begin analyzing data from the very first interview. I then used this information to continue to build a theory throughout the work. To do this, I recalled that "the research process itself guides the researcher" (Corbin \& Strauss, 1990, p. 6). Through persistent scrutiny of the participants' responses, I knew what information should be retained for analysis and what should not, regardless of how fascinating it may seem to me personally. I had to maintain scrutiny of my own biases and my positionality throughout this process to prevent from getting distracted by any single topic that did not inform my theory. This concept will be directly related to my trustworthiness as a researcher in the following section.

\section{Trustworthiness and Credibility}

In this section, I will describe threats to the trustworthiness and limitations of my research in an effort to express my understanding of triangulation in research (Creswell, 2017) and to explain how I will do my best to avoid any shortfalls that may come from my own biases. My perceived limitations include the time and extent of my data collection, the nature of my data collection site, and the nature of my research.

One criticism of qualitative research is that it is difficult to replicate, and this can create concern with regard to credibility and transferability. This relates to trustworthiness of me as a researcher and the credibility of my study and information provided herein. Trustworthiness includes the transferability of this research to other institutions and populations, the dependability and confirmability of the information I provide, and the credibility of my study (Creswell, 2017). Credibility is the ability of the audience to know and understand the environment or conditions in which a study is being conducted, whereas, transferability is the assurance that the research can be replicated by another researcher and obtain similar results, or an explanation can be made for differences found (Tierney \& Clemens, 2011). These checks and balances are vital for credibility and trustworthiness in any study.

Prolonged contact is one of the major tenets of research (Creswell, 2017). It can be difficult for a researcher to confirm the nature of their data if only collected for a brief moment. A distinct limitation of this study is related to the timing of the data being collected. Because the data collection site I selected operates on semesters, my access to students was limited by their completion of the academic year occurring only one month after the beginning of data collection. To mitigate this time constraint and inability to reconnect with the students at a later time, I made my best effort to obtain rich, thick descriptions of the phenomenon of faculty and staff connectedness on student success throughout my interactions with the participants. Due to students not often checking email and, even less frequently when school was out of session, I do not believe I was able to collect as many interviews as I would have mid-year; however, I believe saturation was met regardless of the low number of interviews. Frequent reoccurrence of themes was present in the interviews that were obtained, which

Journal of the Scholarship of Teaching and Learning, Vol. 21, No. 2, June 2021. josotl.indiana.edu 
began to present no new information. Being able to describe the information I collected in detail allows the audience to understand how I reached the conclusions I found and allows other researchers to believe they too could have come to the same conclusion in a similar setting, which makes my findings credible (Tierney \& Clemens, 2011).

Another limitation in my research is the that the data I collected came from an HSI. Federal law requires that for an institution to be classified as an HSI, it must have at least $25 \%$ of the student population identify as Hispanic and must have a high enrollment of students in need of federal funding (Department of Education, 2015). Ultimately, this means that the population of students I analyzed may not be the best predictor of the entire college student population. Due to the nature of an HSI, students in this setting have different experiences than some students may experience at other institutions. Some of the data I collected and interview information I tracked were related to how the students at my data collection site felt different than their peers at other institutions. This information will be discussed further in the discussion section of this study. I believe the study is still transferable to the general college student population, but efforts should be made to find as many students from different backgrounds and experiences as can be located to ensure this data does is representative of a larger college student population. It is possible, that due to personal life circumstances, students on this campus already had higher self-efficacy ratings due to needs in their lives or, students may have inflated their belief in their personal abilities. I am hopeful that a heterogenous sample of students will help generalize this population for future comparisons. Ideally, another researcher could infer the differences in our data collection sites and determine how applicable my study could be to their data collection site or population (Tierney \& Clemens, 2011). After my data was collected and carefully analyzed, I began to detect patterns in the data and collected my findings.

\section{Findings}

Because the intent of this study was to use a mixed methods approach, I began with quantitative data collection and studied those findings to determine what demographic information related to student success. I then extracted the pertinent information in interviews which I believe shows a thorough picture of the needs students expressed and the factors that contributed to their success.

\section{Quantitative Data}

In this study, 134 participants $(n=135$, missing one participant due to being under age 18 in compliance with IRB requirement) were asked to provide demographic information. Participants provided information related to their race and ethnicity, grade level, income level, major, age, GPA, and hours worked per week. This data was collected in an effort to identify whether or not any demographic could provide a causal relationship to student self-efficacy. In addition to demographic information, participants were asked to provide an estimate of the number of hours they have spent with faculty and staff outside the classroom and lectures. To provide a snapshot of the student population surveyed, these demographics will be identified.

Demographics. Participants in this study ranged from the ages of 18-55; the age of 19 was the mode age, and age 21 was the median age. The indicator of gender in this study was fairly evenly distributed with $58 \%$ of participants identifying as female and $42 \%$ identifying as male. Though the survey allowed for responses in this demographic outside the binary, no participant selected other options. Race and ethnicity were divided into six categories: White, Hispanic, Black, Native American, Asian, and Mixed Race. The majority of participants in this study identified as White at 46\%. Other races indicated included 21\% Hispanic, 20\% Mixed Race, and 8\% Black. This population sample is fairly close to national statistics related to college enrollment (Musu-Gillette et al., 2016). The average

Journal of the Scholarship of Teaching and Learning, Vol. 21, No. 2, June 2021. josotl.indiana.edu 
student in this study indicated their grade level to be between freshman and sophomore year, and the mean GPA was 3.34. While GPA and grade level are typically factors in demographic data, it seemed pertinent to collect more data related to student status outside the classroom to determine if this information was relevant to student self-efficacy. For this study, the average income ranged between $\$ 25,000-\$ 50,000$ and the number of hours worked by each student averaged 17 hours per week. Aside from demographics of this nature, students were asked about their connectedness with faculty and staff through hours spent with each respective employment category. Students reported spending the most time with staff, which included advisors, financial aid, and other administrative offices at around 19 hours per week. Students also reported spending approximately 6 hours per week with faculty outside the classroom, including meeting with faculty after class and during office hours. Each of these demographics were compared to student self-efficacy to determine which of these factors may impact student success.

Assessment tool. Self-efficacy, as mentioned previously, was selected as a dependent variable that could not only determine how successful students think they are in school, but also how much students believe their environment impacts that success. On the 13-item scale used, students selected items asking them how effectively they believe they are able to learn, how apt they believe they are to figure things out on their own, how well they believe they obtain the skills needed to develop and use new information, how important they think it is to accomplish tasks, and how confident they believe they are in their ability to be a successful college student. On a scale of 13-65 (based on a 13-item, five-point Likert scale) the average rating students gave themselves was 56 . This high score indicates that the majority of students surveyed are very confident in their ability to be successful. The lowest score recorded on the self-efficacy scale was a 37/65. The modal responses for the self-efficacy score were 65 (11 responses), 58 (11 responses), and 52 (10 responses). Beyond gathering demographic data, this information was compared to self-efficacy scores to identify if any of these independent variables contributed to higher self-efficacy.

Regression Analysis. An ANOVA showed a significance level of $p>.05\left(R^{2}=.160, F(10,92)=\right.$ 1.75), which indicates that the model used is an insignificant predictor of the independent variables (Gender, RaceEthinicity, Grade, GPA, Income, HoursWorkedWeek, Major, FacultyContact Hours, StaffContactHours) abilities to impact self-efficacy. After conducting a multiple regression of independent variables (demographics and survey information) to predict student self-efficacy, the data shows that the majority of independent variables in this study (Gender, RaceEthinicity, Grade, GPA, Income, HoursWorkedWeek, Major, FacultyContact Hours, StaffContactHours) are poor predictors of student self-efficacy, as indicated in Table 1. The single significant variable in this study was Age $(t=2.23, p<$ $.05, s e=.14)$. In this model, the data suggests that the older the student, the more confident they are in their ability to succeed. Limitations will be discussed in a later section to discuss why this may have occurred and other factors to consider for future research.

Journal of the Scholarship of Teaching and Learning, Vol. 21, No. 2, June 2021. josotl.indiana.edu 
Ferguson

Table 1. Standard Multiple Linear Regression of the Effect of Age, Gender, Race and Ethnicity, Grade Level, GPA, Income, Hours Worked per Week, College Major, Faculty Contact Hours, and Staff Contact Hours on Student Self-Efficacy.

\begin{tabular}{|c|c|c|c|c|c|c|}
\hline$\overline{\text { Total SE }}$ & Coef. & Std. Err. & $\mathrm{t}$ & $\mathrm{p}>|\mathrm{t}|$ & \multicolumn{2}{|c|}{ [95\% Conf. Interval] } \\
\hline Age & .309 & .138 & 2.233 & $.028^{*}$ & .034 & .583 \\
\hline Gender & .355 & 1.294 & .274 & .785 & -2.215 & 2.924 \\
\hline RaceEthnicity & -.275 & .279 & -.984 & .328 & -.829 & .279 \\
\hline Grade & .063 & .573 & .109 & .913 & -1.075 & 1.201 \\
\hline GPA & -.395 & 1.485 & -.266 & .791 & -3.344 & 2.554 \\
\hline Income & -.097 & .591 & -.163 & .870 & -1.271 & 1.078 \\
\hline HoursWorkedWeek & -.073 & .044 & -1.678 & .097 & -.160 & .013 \\
\hline Major & .465 & .275 & 1.692 & .094 & -.081 & 1.011 \\
\hline FacultyContactHours & .077 & .041 & 1.889 & .062 & -.004 & .157 \\
\hline StaffContactHours & .000 & .003 & -.069 & .945 & -.007 & .006 \\
\hline Constant & 50.319 & 6.299 & 7.989 & .000 & 37.810 & 62.829 \\
\hline
\end{tabular}

Note. ${ }^{*} p<.05$

\section{Qualitative Data}

Qualitative results showed the students' most consistent factors reported as imperative in their success. Though students' understanding of the difference between faculty and staff was not readily apparent, these factors clearly permeated the students' understandings of what they felt made them successful and held them back. These factors included staff and faculty training, institutional culture, and areas of support.

Staff and Faculty Training. Throughout qualitative data collection, it was readily apparent that one of the overarching themes indicated by students was a need for training for both faculty and staff on campus. Students believed that training should include better communication and knowledge of resources. This theme emerged in discussion around both staff and faculty, but for fairly different reasons.

Students believed communication was lacking related to communication due to staff simply not having a strong understanding of their roles on campus and how to complete tasks. One student, Martha, eluded to her experience as a first-generation college student by stating, "They [staff] couldn't explain things in a way I could understand it. I was so confused." Martha, who is now an employee at the institution strives to help students in similar situations navigate college life but reports that this 
lack of communication "lost me a full-ride scholarship". Martha was a military veteran and a first-time college student who did not understand how funding worked, and after a rough semester, she simply left the campus and did not complete the proper paperwork to maintain her funding. This lack of communication resulted in her returning to school and taking twice as long to complete her degree due to funding issues. Thankfully, Martha was able to persist, but not all students do. Martha was not the only student with financial woes related to poor communication of university staff. Another student, Mohammed, shared that as an international student, he felt that, "[financial aid] wanted to help me, they just don't know what they're doing". Mohammed felt that his communications with staff in this area just did not have a solid understanding of international student requirements and resources, which resulted in him being told, "Sorry, I can't help you." by a number of staff members. Mohammed felt that some of his interactions in these areas were condescending and made him struggle more as a student with an already challenging immersion into a new culture. In addition to feeling that more training is needed related to communication and understanding different student populations, others felt that staff were absent throughout their college careers.

Though it is not uncommon for students to not understand or be aware of how college administration works, some students eluded to the fact that this is frustrating for them and made them feel like they have no control over their educations or their futures because they are not a part of the process. Students felt that more training should exist around communication with students and completing tasks that are begun by staff. Some students mentioned a lack of follow-through from staff, and while offices like TRiO and Advising are great and make them feel incredibly welcome, students sometimes felt like a number. One student, Maria, said she loved some of the services on campus, but more than once, she would go to an office for help and noted that they "don't get me all the way through to the end because they start helping me then disappear". She did not feel that staff cared about her enough to check on her progress or success to see if she needed further assistance. Other students believed similarly that they were passed around between offices but sent in different areas with no clear direction. Martha shared that when she was in school the second time, she really felt that staff took the time to walk her from office to office, and that special touch was helpful so those people could help her explain her needs in a way the other administrators or staff would understand. Martha felt important in these moments and shared her belief that "those staff members really wanted to help us be successful". Another pair of students, Amanda and Mario, mentioned their concern that there is a lack of transparency when it comes to upper administration and decisions made on their behalf. Those students indicated that administration should "show their faces more" because they would like to be connected to the people they believe determine their futures. Students did not really tend to differentiate between staff and faculty in these discussions. It was interesting to see that the concerns they had for staff were still fairly similar to those they have for faculty.

With regard to training, students felt that faculty are remiss by not communicating more with staff to better understand campus resources. Maria, a student with a self-disclosed disability, expressed that she did not think faculty took her disability seriously. In essence, Maria felt that she has to fight with faculty to get equitable treatment in the classroom. Maria stated that faculty "need more training to understand what's out there so they can teach it to the students". This was a common theme when students discussed their involvement with faculty. Another student stated they feel like they have to fight with new faculty each year to be compliant with their ADA needs and wanted faculty to know that, "We're not trying to make them do more work! We just want to perform to our highest ability." Other students mentioned that, in some courses, they felt like faculty, similar to staff, just pass them off to someone else. In one example, Mario mentioned tutoring and how he had gone to faculty to request assistance in a topic he did not understand. In turn, he was told to "go to the tutoring center if he needed help". Mario expressed his frustration by stating, "We pay them to teach us in class, not to learn from a tutor who teaches completely different!" Amanda, a graduating senior, mentioned that

Journal of the Scholarship of Teaching and Learning, Vol. 21, No. 2, June 2021. josotl.indiana.edu 
she sometimes felt like faculty "don't care about me and don't want to help me". Amanda said this made her "not care about getting good grades". This could be devastating to a student who is doing their best and then experiences someone who does not seem to want to help them. This lack of communication with students and lack of training seems to be something that could prevent a student from persisting.

Whether it be inside the classroom or outside, it was very apparent that students just want to be heard and be treated like they matter on campus. Students felt that communication and training were two things that were desperately needed for both faculty and staff. Later, in the discussion section, I will explain how I think campuses can do better in this area and be more supportive of the students they work to educate.

Institutional Culture. One of the major factors contributing to data collection at this research site is the nature of the institution. As noted, this site is an HSI, with the culture at this location being of particular note due to the requirements of the campus to operate and receive funding. When students were prompted, and times when it was not mentioned in the interview, students made mention of the Hispanic culture of the campus. Students made mention that they were disappointed in the fact that their culture, as those who identify as Hispanic, was not as celebrated as they anticipated by attending an HSI and they felt "there is no support for it". Students mentioned that, while they did not particularly choose to attend the school due to its HSI status, they were disappointed that there is not enough culture and traditions celebrated on the campus because major holidays and events "seem to be ignored". Students also indicated that they were disappointed in the fact that it seemed that their culture was not celebrated on the campus sharing that "Hispanic means more than just Mexican" and the cultural recognition on campus should include other heritages and traditions.

Students mentioned that they did not feel there was support on campus for despite its HSI status, and students felt the only place they really felt that being Hispanic was appreciated was in the Spanish department on campus. Students mentioned this in a positive regard toward faculty in that they immediately felt "like family" with those in the Spanish department because they experienced similar backgrounds, or they were reminded of family members close to them. When asked to extrapolate why this was the case, Mario believed it was a direct result of "Spanish culture being more family oriented". Alternatively, students who identify as Hispanic reported feeling "other than" because of their ethnicity, especially when it was noticed that they did not speak fluent Spanish. Martha mentioned that not speaking Spanish but wanting to identify with her Hispanic culture made her feel like "an imposter".

One student, Mario, mentioned he felt a strong "fear of speaking in class and sounding like a dumb Mexican", so he just did not participate. Mario's peers alternatively mentioned that some faculty attempted to "tokenize" other students, for example, expecting one Black student in class to speak for all Black students. Additionally, students felt that staff made these errors by only suggesting Chicano courses to Chicano students without first asking if this is something they even had an interest in or, at times, assuming a student spoke Spanish because they had a Spanish last name. Students felt that staff made suggestions for them in earnest but were making too many assumptions about who they looked like and not asking what their true interests were. Overall, the HSI status of this campus seemed to be of less interest to students who did not identify as Hispanic. Other students mentioned other facets of the campus culture they enjoyed.

Some of the interests that students mentioned were that they enjoyed "making friends easily on a smaller campus", they liked the "smaller class sizes" and they felt like they had more one on one time with faculty of shared interests and got "real explanations instead of just going over the syllabus". Students mentioned they enjoyed that being at a smaller campus was similar to high school to make things less "scary" but that it was a large enough campus to feel freedom. Students shared that one of their favorite things was that faculty and staff knew their names and could address them as individuals

Journal of the Scholarship of Teaching and Learning, Vol. 21, No. 2, June 2021. josotl.indiana.edu 
on campus. Students made it very clear that these areas of support were one of the major factors in their success.

Support. It comes as no surprise that support is one of the most important factors of student success according to the students in this study. Students very clearly articulated that some of their favorite characteristics of faculty and staff alike, aside from those previously mentioned, were those in the campus community who are friendly and helpful and had mutual connections with them.

Students mentioned that the more prevalent factor in their selection of support faculty and staff included their mutual connections more than their race, ethnicity, or shared language. Students stated that faculty and staff who took the time to sit with them and actually explain information and new concepts were strong motivators for them. Amanda, in her interview, shared that "when my professors try to relate to me, it makes me try harder". Additionally, female students in particular shared that they appreciated faculty and staff who gave them confidence to speak up and be themselves. Amanda explained a situation in which she took a social work course where a professor really empowered her to "be a strong woman and have a voice". She shared this as one of the most important parts of her college career so far. Amanda also shared that, in addition to supportive professors, she really felt engaged with ones who really shared with them their resources and what expectations they mutually had for one another. Students felt that alongside engagement and mutual connection, help with life beyond the classroom was also a strong area of support.

While there were some instances in which students felt unsupported by faculty inside the classroom, faculty were frequently mentioned when it came to support outside the classroom in that the students really felt that those faculty who went above and beyond were ones who taught them how their learning in the classroom could be applied to real life concepts. Students stated that faculty who taught them individual life skills were also important to them. Michael shared that his favorite professor was someone in his honors college who talked to him about how he would apply his degree in the future and made him think deeply and considerately about his career path and life beyond college. Michael felt that, as a high performing student, actions that "show they want me to succeed in life and not just pass their class" were important to him and that he appreciated the challenges that brought to him as a student.

With regard to staff support, students really felt engaged when staff helped them get jobs on campus as work study so they could learn and grow professionally and academically. Students mentioned that working on campus was one of the things they felt forced them to meet other students, faculty, and staff and that those relationships had served them well in their college careers. Student who had work study on campus mentioned they had experiences with staff who "help us be our best self". These on campus positions also seemed to be a pathway to friendships which students mentioned were positive for their success as well. Overall, students shared various preferences and dislikes about being on this particular college campus. In relation to prior research, the students interviewed did not necessarily seem to have unique experiences related to their peers, however, this study was able to discuss relationships with staff also in depth. All of this information culminates into what I believe are some important pieces that could strongly impact student self-efficacy and success if a few simple changes were made to higher education and how it is operated by both faculty and staff.

\section{Discussion}

To better understand the culmination of the data and information gathered here, it is pertinent to discuss the implications of practice these outcomes may have as well as the limitations of this study. What follows is an analysis of what future practice may need to consider in order to better understand or replicate this data.

Journal of the Scholarship of Teaching and Learning, Vol. 21, No. 2, June 2021. josotl.indiana.edu 


\section{Implications}

This study made it clear that students believe very highly of their ability when it comes to self-efficacy. This calls to question what the true roles are of faculty and staff on college campuses and whether or not those roles are truly being fulfilled. During the qualitative portion of this study, students shared their understanding in the problems of practice stem from insufficient training and communication and poor support of institutional culture.

When considering what interactions may be linked to student self-efficacy, this body of research seems to indicate those interactions could be mostly negative. When students do reach out for help and support, they are sent from office to office to get answers to questions by staff, which reduces their ability to feel successful. By faculty, students are told to go to tutoring and as a result feel passed off, which could lower self-efficacy because they were vulnerable in asking for help in the first place. Students coming somewhere new and not knowing all of the answers but then being passed around indicated they fell victim to imposter syndrome. Imposter syndrome is the experience in which students may feel like they are incompetent or inadequate which induces a fear of failure and selfdoubt (Craddock et al., 2011). Knowing imposter syndrome leads to a lower self-efficacy, it calls into question how much these feelings of doubt could in fact impact students' perceived interactions with faculty and staff, as well as, how much these feelings or beliefs impact retention and GPA. This information, coupled with knowledge that inadequate training, passing students around, and poor communication result in negative experiences for students, provides evidence that these elements have serious implications for how institutional culture impacts self-efficacy.

In addition to feeling imposter syndrome on campus because students felt unable to navigate coursework or clerical information, being on an HSI campus also gave students feelings of inadequacy. Students who came to this particular campus seeking support through their culture and background felt disappointed and let down. Interestingly, on a campus where Hispanic heritage should be felt more appreciated, Hispanic students still reported feeling the same as their peers at other institutions without the HSI indication (Baker, 2013; DeFreitas, 2012). Knowing that colleges and universities receive funding to carry HSI status, but students do not believe those needs are being met, it could imply that there needs to be more oversight from the funding sources to ensure these students' needs are met on an HSI campus. Some research has shown that colleges have been negligent in this area and has claimed that HSI campuses are further colonizing the groups they are being funded to liberate (Garcia, 2017).

The data collected here strongly suggests that intentional assessment needs to be conducted on campuses to determine what training may be needed for both faculty and staff so that students can better navigate these new worlds they find themselves in. Communication is something that spans across academic disciplines and across staff support areas. Colleges and universities have an obligation to ensure that communication is shared and understood by on the various entities on campus that impact student development. Cross training and resource training should be required so that students are not left doing the work of the staff and faculty they are paying to teach and support them. It is clear, with regard to institutional culture, that not only do HSIs need to be more aware of their support or lack thereof, but most likely, higher education should consider these shortcomings overall to better support student populations. There is a lot of talk about supporting students and diversity and inclusion, but standards should be reviewed, and some accountability should be required to ensure these promises are fulfilled. Students clearly need more than lip service to be successful on our campuses. Because this study was conducted at an HSI, it is important to consider what limitations related to this status and what other elements may have impacted this research.

Journal of the Scholarship of Teaching and Learning, Vol. 21, No. 2, June 2021. josotl.indiana.edu 


\section{Limitations}

There were limitations to this study that have been mentioned throughout the analysis of this data. Some of those limitations relate to the research site, sample size, data analysis conducted, and student perceptions. Although these limitations seem to have had little impact on the overall result of findings, it is important to clarify some of these limitations and considerations for future research.

The HSI status of the data collection site has been mentioned throughout. This theme became a repeated concern with the students in this study. It is important to consider what other things students may have discussed had they not been hyper focused on this status. Students at a highly athletics focused campus may have mentioned athletics as a crutch, students at an HBCU may have similar concerns with regard to HBCU status, etc. Though this theme was incredibly important to these students at the data collection site, it is likely another theme may have emerged on a different campus. Though this information cannot be transferred to all college campuses, it is still important to consider what cultures exist on other campuses that could be relevant and creating negative experiences for students or impacting their self-efficacy. Another limitation related to data collection is the sample size used.

In general, a study with a larger effect size is ideal (Dillman, 2007). For this particular population of roughly 5,000 students, a sample with a 95\% confidence interval would have been around 350 surveys. For my data, I conducted about half the needed sample to obtain a 95\% confidence interval. Due to time constraints, collecting 350 surveys was not possible for this study. To reduce the sampling error for future research, a higher number of surveys should be collected to ensure higher levels of precision in quantitative analysis. In addition to a smaller sample size, it is important to note the type of regression conducted for this study as a possible limitation.

For the quantitative data analysis of this study, 10 independent variables were compared against one dependent variable through the use of regression analysis to determine if any relationships existed. Being a novice quantitative researcher, I am uncertain whether or not this data comparison had any adverse impact on my findings. A more seasoned researcher may have known to separate some variables during data comparisons to obtain a different result. It is possible that having 10 independent variables in one regression model made an effect look insignificant when it was significant, or vice versa. Further data collection and investigation could correct this limitation in future findings.

One final limitation also related to the quantitative analysis is with regard to the student responses. Careful consideration was made when identifying a self-efficacy scale with a high alpha to ensure reliability. What I cannot be certain of in this study is the testing bias that may have come from this scale. Because a five-point Likert scale was used, it is possible there was some halo effect or leniency error in this design (Shultz, Whitney, \& Zickar, 2014). It is clear that students rated themselves very highly on the scale, as the lowest rating indicated on any one question was a three or higher. It should be considered that the students were given no incentive for this study and no reason to take their time to answer the questions with great thought and consideration. Though, as researchers, we want to think the data we are collecting is as accurate as possible, there is the potential for our participants to give the answer we want to see or to just give an answer that is easy. An easy solution for this limitation would be to reverse some of the items on the scale for future research to require participants to read items more closely (Shultz et al., 2014). Another thing to take into consideration, as mentioned earlier, is the time of data collection and its impact on student response rates due to the summer semester occurring during that time of data collection. It is possible a higher sample could have been obtained had more students physically been on campus at the time of collection.

Overall, the limitations listed here do not deem this data impractical for future research. There is always some level of error in testing and sampling that will occur in any study. Future research

Journal of the Scholarship of Teaching and Learning, Vol. 21, No. 2, June 2021. josotl.indiana.edu 
should consider these limitations and attempt to find ways to ameliorate them in subsequent data comparison and analysis. It would be helpful to know what limitations my data collection site had on my study and if these findings could be generalized across the college going population. Knowing these limitations, however, I believe there are still some strong conclusions that are relevant and impactful for guiding implications for practice for universities using the data collected here.

\section{Conclusion}

The data is clear that a link between social capital and self-efficacy exists on college campuses but eludes to the fact that other research may have been looking at the wrong elements to define these relationships. Prior research on self-efficacy has determined that environment and social interactions can increase self-efficacy (Bandura, 1994; Pajares, 1996) and has demonstrated that similar characteristics of others in the environment can make a difference (Baker, 2013; DeFreitas, 2012). However, this body of research indicates that, at least at the college campus picked for this research site, race and ethnicity are not as important to students as previously believed. What matters most to students is their ability to trust faculty and staff to prepare them for life and a career. The theory that exists then, to (1) explain the interactions correlated to student success and to (2) determine how students perceive these interactions and (3) what impact the relationships may have on student retention and GPA, is that while students believe highly in their own self-efficacy and this ability increases with age, staff and faculty need to provide this support and complete their promises to make this perception reality. This support then, needs to come in the form of training, better communication, and support of the anticipated college environment.

Colleges and universities have the potential to use these social constructs and interactions for the betterment of students through more required interaction and support from faculty and staff, which could result in higher retention and persistence. In looking at comparative research about selfefficacy, students who feel more successful can truly be more successful (Baker, 2013; Brown, 2001; Gnebola, 2015). It is up to college campuses to find ways to increase students' positive perceptions of themselves and induce more meaningful interactions with faculty and staff. My belief is that this study can lead the way in making that happen. There is still much work to be done in this arena, and funding will continue to compound the issue; however, colleges cannot expect to see students succeed if relationships with faculty and staff do not improve, and as a result, must make investments in order to ensure those downfalls are avoided.

Journal of the Scholarship of Teaching and Learning, Vol. 21, No. 2, June 2021.

josotl.indiana.edu 


\section{Appendix}

\section{Appendix 1. Demographic Data Collection.}

\section{Demographic Information}

Age:

Gender: Male Female Non-binary Prefer to Self-Describe

Prefer Not to Answer

Race/Ethnicity (circle all that apply): White Hispanic or Latino Black or African American

Native American or American Indian

Asian/Pacific Islander

Other

Grade: Freshman Sophomore Junior Senior Other

Cumulative GPA:

Household Income (include parents, if applicable):

$\$ 0-25,000 \quad \$ 25,001-50,000 \quad \$ 50,001-100,000 \quad \$ 100,000+$

Hours Worked per Week (include work study and any other employment):

Major:

\section{Faculty/Staff Contact Information}

How many times have you had contact with faculty members during office hours or during other events on campus? (Faculty members are defined as someone who teaches courses and does not include your advisor.)

How many times have you had contact with University staff either during advising meetings, other formal meetings, or during informal conversations at university events? (University staff is defined as someone who works at the University but does not typically teach classes. This can include an advisor, student affairs staff, or admissions/financial aid employees.)

I believe the interactions I stated above were positive because:

I believe the interactions I stated above were negative because:

I would like to participate in phase two of this research by being contacted at: (enter a valid phone number or

email address) 


\section{Self-Efficacy Formative Questionnaire}

Please CHECK ONE response that best describes you. Be honest, since the information will be used to help you in school and also help you and other students become more prepared for college and careers. There are no right or wrong answers! Feel free to leave any questions blank that you do not wish to answer.

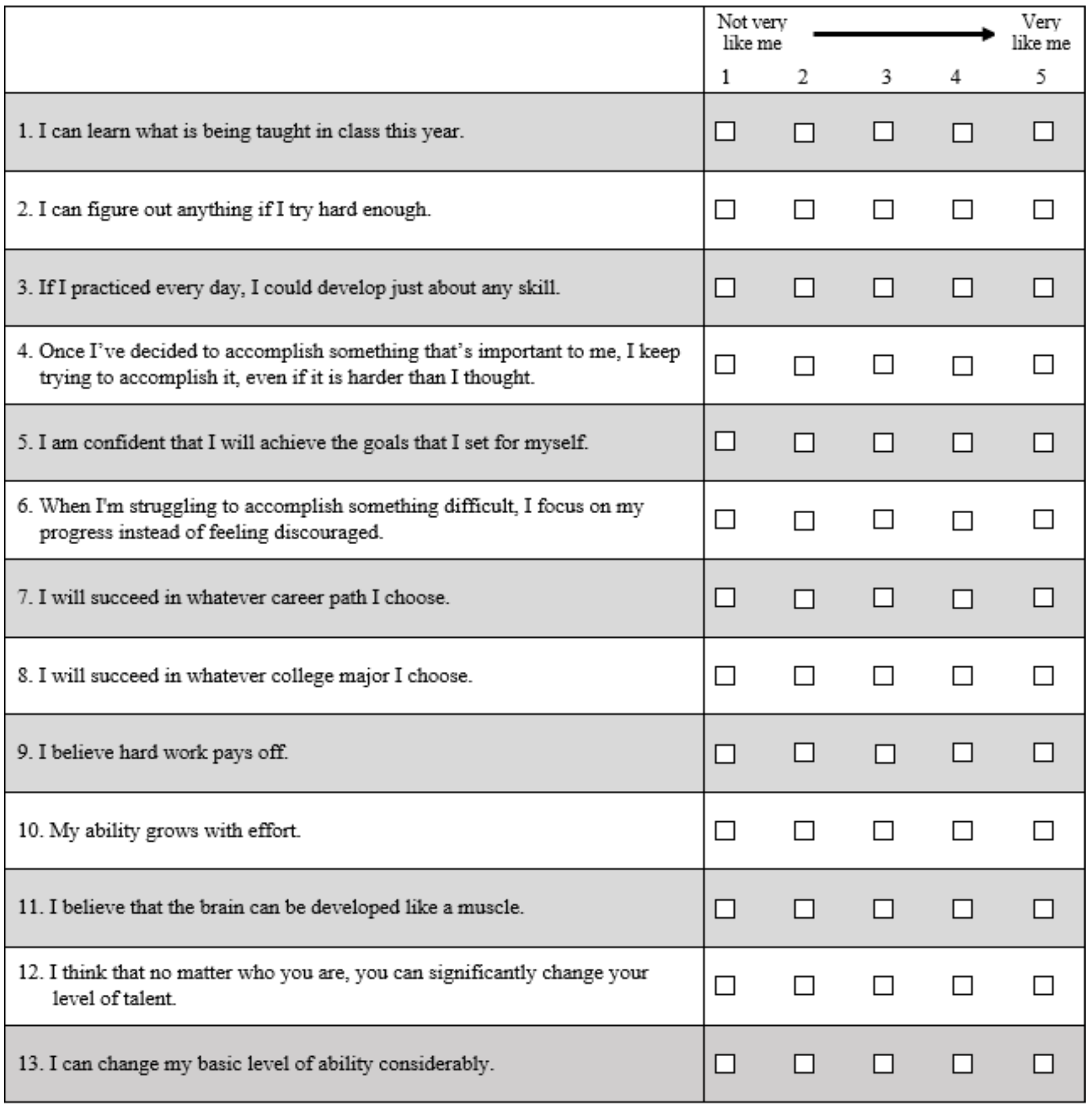

Gaumer Erickson, A.S. \& Noonan, P.M. (2018). Self-efficacy formative questionnaire. In The skills that matter: Teaching interpersonal and intrapersonal competencies in any classroom (pp. 175-176). Thousand Oaks, CA: Corwin. 


\section{Appendix 2. Qualitative Collection-Interview Protocol.}

Hello.

Thank you for being willing to help me with collecting this data today. How are you doing? Respond.

So, do you remember what this study is about?

Respond.

I want to give you another consent form to sign describing how this information will be different from the other information you already provided. Is that okay?

Respond.

(Give informed consent and explain while they review it.) So, I hope to use this information to determine how confident students on college campuses are and what universities can do to make you more confident. I am trying determine whether or not your relationships with faculty and staff have any impact on your success. Does this all make sense?

Respond.

I expect this interview to take about an hour. Does that time work for you?

Respond.

Feel free to elaborate when you think it is important and ask me any clarifying questions if one of my questions does not make sense, okay?

Respond.

I also wanted to record this just so I don't miss anything important you tell me. Is that okay with you? Respond.

(Turn on recorder.) Let's get started!

1. Tell me a little about your college experience so far.

2. Tell me about your experiences connecting with faculty and staff while on campus.

3. Do you think faculty and staff connection is important to student success?

4. Can you share an experience with me you have had, good or bad?

5. Is there anything that made you want to connect with that faculty or staff member?

6. Are there particular characteristics that you look for in a faculty or staff member to make you desire a connection with them?

7. Are there any connections you have had that were more negative/positive (depending on the initial response)? What was it about those connections that were different?

8. How could faculty or staff better connect with you as a student?

9. What resources have you used on campus to help improve your performance as a student?

10. Were those resources beneficial for you?

11. What resources would you like to see on campus to improve your self-confidence or make you a better student?

Thank you so much for sharing these experiences with me. I think this will be super helpful when I begin to report this research. I want to remind you that you are welcome to see my completed study if you would like to see it. My email address is on the consent form I gave you a copy of so please contact me any time for questions.

Journal of the Scholarship of Teaching and Learning, Vol. 21, No. 2, June 2021. josotl.indiana.edu 


\section{References}

Baker, C. (2013). Social support and success in higher education: The influence of on-campus support on African American and Latino college students. The Urban Review, 45(5), 632-650. doi:10.1007/s11256-013-0234-9

Bandura, A. (1994). Self-efficacy. Encyclopedia of Human Behavior. New York: Academic Press.

Brown, S. P., Ganesan, S., \& Challagalla, G. (2001). Self-efficacy as a moderator of informationseeking effectiveness. Journal of Applied Psychology, 86(5), 1043-1051.

Charmaz, K. (2006). Constructing grounded theory. Thousand Oaks, CA: Sage Publications.

Coleman, J. S. (1990). Foundations of social theory. Cambridge, MA: Belknap Press of Harvard University Press.

Corbin, J. \& Strauss, A. (1990). Grounded theory research: Procedures, canons, and evaluative criteria. Qualitative Sociology, 13(1), 3-21.

Corbin, J., \& Strauss, A. (2007). Basics of qualitative research: Techniques and procedures for developing grounded theory (3rd ed.). Thousand Oaks, CA: Sage Publications.

Craddock, S., Birnbaum, M., Rodriguez, K., Cobb, C. \& Zeeh, S. (2011). Doctoral students and the impostor phenomenon: Am I smart enough to be here? Journal of Student Affairs Research and Practice, 48(4), 429-442.

Creswell, J.W. \& Poth, C.N. (2017). Qualitative inquiry and research design: Choosing among five approaches (4th ed.). Thousand Oaks, CA: Sage Publications.

DeFreitas, S. C. \& Bravo, A. (2012). The influence of involvement with faculty and mentoring on the self-efficacy and academic achievement of African American and Latino college students. Journal of the Scholarship of Teaching and Learning, 12(4), 1-11.

Department of Education (2015). Federal agencies investing in Hispanic education. White House Initiative on Educational Excellence for Hispanics. Washington, D.C.

Dillman, D. A., Smyth, J.D., \& Christian, L. M. (2007). Internet, mail, and mixed mode surveys: The tailored design method. Hoboken, NJ: Wiley \& Sons.

Garcia, G. A. (2017). Decolonizing Hispanic-serving institutions: A framework for organizing. Journal of Hispanic Higher Education, 17(2), 132-147.

Gaumer Erickson, A.S. \& Noonan, P.M. (2018). Self-efficacy formative questionnaire. In The skills that matter: Teaching interpersonal and intrapersonal competencies in any classroom (pp. 175-176). Thousand Oaks, CA: Corwin.

Glaser, B. G. \& Strauss, A. L. (1967). The discovery of grounded theory: Strategies for qualitative research. Chicago, IL: Aldine Publishing.

Gnebola, M.A. (2015). Examining relationships among faculty-student interactions, academic self-efficacy, selfregulation, and academic achievement of undergraduate students. George Mason University, VA.

Guest, G., Bunce, A., \& Johnson, L. (2006). How many interviews are enough? An experiment with data saturation and variability. Family Health International, 18(1), 59-82.

Hatch, J. A. (2002). Doing qualitative research in education settings. Albany, NY: SUNY Press.

Jacob, S. A. \& Furgerson, S. P. (2012). Writing interview protocols and conducting interviews: Tips for student new to the field of qualitative research. The Qualitative Report, 17(42), 1-10.

Jones, S. R., Torres, V., \& Arminio, J. L. (2006). Negotiating the complexities of qualitative research in higher education: Fundamental elements and issues. New York, NY: Routledge.

Maxwell, J. A. (2013). Qualitative research design: An interactive approach (3rd ed.). Thousand Oaks, CA: Sage Publications.

Musu-Gillette, L., Robinson, J., McFarland, J., Kewal Ramani, A., Zhang, A., \& Wilkinson- Flicker, S. (2016). Status and trends in the education of racial and ethnic groups 2016 (NCES 2016-007).

Journal of the Scholarship of Teaching and Learning, Vol. 21, No. 2, June 2021.

josotl.indiana.edu 
U.S. Department of Education, National Center for Education Statistics. Washington, DC. Retrieved from http://nces.ed.gov/pubsearch

Pajares, F. (1996). Self-efficacy beliefs in academic settings. Review of Educational Research, 66(4), 543578.

Saldaña, J. (2009). The coding manual for qualitative researchers. Thousand Oaks, CA: Sage Publications.

Shultz, K. S., Whitney, D. J., \& Zickar, M. J. (2014). Measurement theory in action: Case studies and exercises. New York, NY: Routledge.

Seibert, S. E., Kraimer, M. L., \& Linden, R. C. (2001). A social capital theory of career success. The Academy of Management Journal, 44(2), 219-237.

Strauss, A. (1987). Qualitative analysis for social scientists. New York: Cambridge University Press.

Tierney, W. G., \& Clemens, R. F. (2011). Qualitative research and public policy: The challenges of relevance and trustworthiness. Higher Education: Handbook of Theory and Research, 26, 57-83.

Tinto, V. (1975). Dropout from higher education: A theoretical synthesis of recent research. Review of Educational Research, 45(1), 89-125. https://doi.org/10.3102/00346543045001089

Wood, J. L., Hilton, A. A., \& Johnson, R. M. (2014). The effect of self-efficacy on academic and social integration: An investigation of students of color in the community college. College Student SelfEfficacy Research Studies, 3-25. Maryland: University Press of America.

Zimmerman, B. J. (2000). Self-efficacy: An essential motive to learn. Contemporary Educational Psychology, 25(1), 82-91. 